\title{
$\mathrm{BMJ}$
}

\section{Risk of respiratory morbidity in term infants delivered by elective caesarean section: cohort study}

\author{
Anne Kirkeby Hansen, research fellow, ${ }^{1}$ Kirsten Wisborg, staff specialist, ${ }^{2}$ Niels Uldbjerg, professor, ${ }^{3}$ \\ Tine Brink Henriksen, associate professor ${ }^{2}$
}

${ }^{1}$ Perinatal Epidemiology Research Unit, Aarhus University Hospital, Brendstrupgaardsvej 100, Skejby, 8200 Aarhus N, Denmark

${ }^{2}$ Department of Paediatrics, Aarhus University Hospital

${ }^{3}$ Department of Obstetrics and Gynaecology, Aarhus University Hospital

Correspondence to: A K Hansen AKH@svf.au.dk

doi:10.1136/bmj.39405.539282.BE

\section{ABSTRACT}

Objective To investigate the association between elective caesarean sections and neonatal respiratory morbidity and the importance of timing of elective caesarean sections.

Design Cohort study with prospectively collected data from the Aarhus birth cohort, Denmark.

Setting Obstetric department and neonatal department of a university hospital in Denmark.

Participants All liveborn babies without malformations, with gestational ages between 37 and 41 weeks, and delivered between 1 January 1998 and 31 December 2006 (34 458 babies).

Main outcome measures Respiratory morbidity (transitory tachypnoea of the newborn, respiratory distress syndrome, persistent pulmonary hypertension of the newborn) and serious respiratory morbidity (oxygen therapy for more than two days, nasal continuous positive airway pressure, or need for mechanical ventilation).

Results 2687 infants were delivered by elective caesarean section. Compared with newborns intended for vaginal delivery, an increased risk of respiratory morbidity was found for infants delivered by elective caesarean section at 37 weeks' gestation (odds ratio 3.9, 95\% confidence interval 2.4 to 6.5$), 38$ weeks' gestation (3.0, 2.1 to 4.3 ), and 39 weeks' gestation (1.9, 1.2 to 3.0). The increased risks of serious respiratory morbidity showed the same pattern but with higher odds ratios: a fivefold increase was found at 37 weeks (5.0, 1.6 to16.0). These results remained essentially unchanged after exclusion of pregnancies complicated by diabetes, pre-eclampsia, and intrauterine growth retardation, or by breech presentation.

Conclusion Compared with newborns delivered vaginally or by emergency caesarean sections, those delivered by elective caesarean section around term have an increased risk of overall and serious respiratory morbidity. The relative risk increased with decreasing gestational age.

\section{INTRODUCTION}

Deliveries by caesarean section continue to increase in both developed and developing countries. Rates as high as 50\% have been reported in some regions of Latin America. ${ }^{1}$
Caesarean section used to be carried out primarily because of obstetric complications or serious maternal illness. Lately many other factors, such as reduced risk to the mother as a result of improved anaesthetic procedures and surgical techniques, elective caesarean section because of breech presentation, or previous caesarean section may have contributed to changes in obstetric practice and patient choice. ${ }^{4}$ Thus increased rates of elective caesarean section without any obvious or generally accepted medical or obstetric indication have been reported to contribute further to the increasing rate of elective caesarean sections. ${ }^{8}$ If no medical indication is present evidence based information about risks and benefits for mothers as well as newborns becomes all the more important for adequate counselling. ${ }^{9}$

Previous studies have shown elective caesarean section to be associated with an increased risk of respiratory morbidity in neonates, ${ }^{10}$ although methodological shortcomings and differences between studies make it difficult to evaluate properly the causality and magnitude of the association.

It is plausible that hormonal and physiological changes associated with labour are necessary for lung maturation in neonates and that these changes may not occur in infants delivered by elective caesarean sections. ${ }^{16}$ Gestational age at the time of elective caesarean section may also be important for respiratory morbidity in neonates. ${ }^{18}$

We evaluated the association between elective caesarean section and neonatal respiratory morbidity in a large cohort of women with high and low risk pregnancies. We also separately analysed the effect of gestational age at the time of elective caesarean section.

\section{METHODS}

Since September 1989 all women scheduled for delivery at Aarhus University Hospital, Denmark have been invited to participate in the Aarhus birth cohort study. ${ }^{19}$ Information has been collected on about 80000 pregnancies and deliveries so far. Women attending routine antenatal care at our department were asked to self complete a questionnaire early in the second trimester. This questionnaire contains information on medical and obstetric history, smoking, alcohol 
intake, marital status, educational level, and occupational status. Information about the course of delivery and the state of newborns was collected immediately after delivery by the midwife, using structured birth registration forms. Before data entry the midwives validated the birth registration forms by comparing them with the medical records using a specific and extensive coding manual. Information about neonatal morbidity has been obtained since 1997 from routine discharge registration forms and a structured coding sheet completed by neonatologists. The neonatal department is tertiary and none of the neonates with respiratory illness were transferred to other hospitals.

\section{Study population}

Between January 1998 and December 2006 our department delivered 41095 live singletons. We included in our analyses all liveborn singletons without congenital malformations of gestational ages 37 to 41 completed weeks, delivered between 1 January 1998 and 31 December 2006 (34 458 pregnancies). This period was chosen because information about neonatal

Table 1 | Neonatal respiratory morbidity in relation to elective caesarean section and maternal characteristics of 34458 pregnant women attending Aarhus University Hospital, Denmark, 19982006

\begin{tabular}{|c|c|c|}
\hline Variables & No of pregnancies & $\begin{array}{l}\text { No (\%) with respiratory } \\
\text { morbidity }\end{array}$ \\
\hline \multicolumn{3}{|c|}{ Delivered by caesarean section: } \\
\hline Yes & 2687 & $112(4.2)$ \\
\hline No & 31771 & $492(1.5)$ \\
\hline \multicolumn{3}{|c|}{ Smoking in pregnancy (cigarettes/day): } \\
\hline 0 & 24387 & $415(1.7)$ \\
\hline$>0$ & 3530 & $52(1.5)$ \\
\hline Missing data & 6541 & $137(2.1)$ \\
\hline \multicolumn{3}{|c|}{ Alcohol intake in pregnancy (units/week): } \\
\hline$\ll 1$ & 23421 & $410(1.8)$ \\
\hline$>1$ & 3993 & $55(1.4)$ \\
\hline Missing data & 7044 & $139(2.0)$ \\
\hline \multicolumn{3}{|l|}{ Parity: } \\
\hline Primiparous & 16769 & $341(2.0)$ \\
\hline Multiparous & 17681 & $263(2.0)$ \\
\hline Missing data & 8 & 0 \\
\hline \multicolumn{3}{|l|}{ Body mass index $\left(\mathrm{kg} / \mathrm{m}^{2}\right)$ : } \\
\hline$<24$ & 20399 & $322(1.6)$ \\
\hline$\geq 25$ & 7421 & $148(2.0)$ \\
\hline Missing data & 6638 & $134(2.0)$ \\
\hline \multicolumn{3}{|l|}{ Maternal age: } \\
\hline$<35$ & 28645 & $484(1.7)$ \\
\hline$\geq 35$ & 5811 & $120(2.1)$ \\
\hline Missing data & 2 & 0 \\
\hline \multicolumn{3}{|l|}{ Marital status: } \\
\hline Married or cohabiting & 25728 & $444(1.7)$ \\
\hline Single & 965 & $15(1.6)$ \\
\hline Missing data & 7765 & $145(1.9)$ \\
\hline \multicolumn{3}{|l|}{ No of years of schooling: } \\
\hline$\geq 10$ & 24563 & $425(1.7)$ \\
\hline$<10$ & 1980 & $35(1.8)$ \\
\hline Missing data & 7915 & $144(1.8)$ \\
\hline
\end{tabular}

morbidity was not complete before 1998 . A subgroup (32580 pregnancies) was constructed to analyse the outcome of low risk pregnancies only. We therefore excluded all pregnancies associated with intrauterine growth retardation $(\mathrm{n}=378)$, diabetes (gestational or overt; $\mathrm{n}=624)$, and pre-eclampsia or hypertension $(\mathrm{n}=959)$. We defined intrauterine growth retardation as birth weight less than $2500 \mathrm{~g}$ in infants born after 36 completed weeks of gestation.

Deliveries were categorised as vaginal, elective caesarean section, emergency caesarean section, and vacuum or forceps. We categorised caesarean sections after start of labour or rupture of the membranes as emergency caesarean sections. Labour was defined as regular uterine contractions with progression of cervical dilation. For our final analyses we categorised deliveries into two groups: elective caesarean section and intended vaginal delivery - that is, all vaginal deliveries and emergency caesarean sections. We measured gestational age in completed weeks on the basis of information reported to the Danish national patient registry.

We considered information only related to newborn admissions to hospital immediately after delivery. The diagnosis of neonatal respiratory morbidity was established from discharge forms on the basis of the following codes from the international classification of diseases, 10th revision: any respiratory distress (DP220, DP228, DP229; n=303), transient tachypnoea of the newborn (DP221; n=289), and persistent pulmonary hypertension of the newborn (DP293; $\mathrm{n}=36$ ). The diagnoses were reported by senior specialists in neonatology. We defined serious respiratory morbidity as that requiring treatment for three or more days with continuous oxygen supplementation, nasal continuous positive airway pressure, or any period of mechanical ventilation $(\mathrm{n}=64)$.

We repeated analyses after exclusion of newborns with meconium aspiration syndrome (DP240; n=93), sepsis (DP369, DP360, DP399, DP362, DA419; $\mathrm{n}=453$ ), or pneumonia (DP239, DJ189, DJ181; $\mathrm{n}=3$ ) because these conditions may cause respiratory symptoms unrelated to delayed transition from fetus to newborn but are associated with intended vaginal delivery.

We carried out bivariate analyses to compare the risk of respiratory morbidity in babies delivered by elective caesarean section with the risk after intended vaginal delivery within each gestational week. For final analysis we compared the risk of respiratory morbidity after elective caesarean section in each gestational week with the risk after intended vaginal delivery at 40 weeks - that is, an adapted intention to treat analysis. This week was chosen as the reference because it had the highest proportion of deliveries among women with intended vaginal delivery $(n=11007,35 \%$ of all intended vaginal deliveries).

We present the association between mode of delivery and respiratory morbidity as odds ratios with $95 \%$ confidence intervals. To evaluate effect modification by gestational age we used stratified analyses. We 
used logistic regression analyses to evaluate potential confounding variables (maternal smoking and alcohol intake during pregnancy, parity, maternal prepregnancy body mass index, maternal age, marital status, and years of schooling). Adjusted odds ratios are also presented for respiratory morbidity but not for serious respiratory morbidity owing to the small number of observations.

\section{RESULTS}

Overall, 2687 liveborn singletons $(7.8 \%)$ were delivered by elective caesarean section at Aarhus University Hospital between 1 January 1998 and 31 December 2006, leaving 31771 women (92.2\%) with intended vaginal delivery of which 2877 delivered by emergency caesarean section. Table 1 shows respiratory morbidity in relation to elective caesarean section and maternal characteristics. The frequency of respiratory morbidity was $1.8 \%(\mathrm{n}=604)$, with $0.2 \%(\mathrm{n}=64)$ having serious respiratory morbidity. In the low risk population the corresponding frequencies were $1.7 \%(n=556)$ and $0.2 \%(\mathrm{n}=57)$.

\section{Respiratory morbidity}

Compared with infants delivered by women intended to have a vaginal delivery, those delivered by elective caesarean section had an increased risk of respiratory morbidity at any gestational age before 40 weeks. A nearly fourfold increased risk was found at 37 weeks' gestation (odds ratio 3.9, 95\% confidence interval 2.4 to $6.5)$ and a threefold increase in risk at 38 weeks' gestation (3.0, 2.1 to 4.3$)$, whereas the risk was doubled in infants delivered at 39 weeks' gestation $(1.9,1.2$ to 3.0; table 2).

Adjustment for potential confounding variables failed to change considerably the risk estimates

Table2 | Odds ratios (95\% confidence intervals) of neonatal respiratorymorbidity after electivecaesarean section and intended vaginal delivery for 34458 pregnancies at Aarhus University Hospital, Denmark, 1998-2006

\begin{tabular}{|c|c|c|c|c|c|c|}
\hline \multirow[b]{2}{*}{ Gestational age + , type of delivery } & \multicolumn{4}{|c|}{ Respiratory morbidity } & \multicolumn{2}{|c|}{ Serious respiratory morbidity* } \\
\hline & No of deliveries & $\begin{array}{l}\text { No (\%) of } \\
\text { infants }\end{array}$ & Odds ratio $(95 \% \mathrm{Cl})$ & Odds ratio $\neq(95 \% \mathrm{Cl})$ & $\begin{array}{c}\text { No (\%) of } \\
\text { infants }\end{array}$ & Odds ratio $(95 \% \mathrm{Cl})$ \\
\hline \multicolumn{7}{|l|}{ All pregnancies } \\
\hline \multicolumn{7}{|l|}{37 weeks: } \\
\hline Elective caesarean section & 261 & $26(10)$ & $3.9(2.4$ to 6.5$)$ & $3.7(2.2$ to 6.1$)$ & $5(1.9)$ & $5.0(1.6$ to 16$)$ \\
\hline Intended vaginal delivery & 1804 & $49(2.8)$ & Reference & Reference & $7(0.4)$ & Reference \\
\hline \multicolumn{7}{|l|}{38 weeks: } \\
\hline Elective caesarean section & 1173 & $60(5.1)$ & $3.0(2.1$ to 4.3$)$ & $3.0(2.1$ to 4.4$)$ & $10(0.9)$ & $4.2(1.6$ to 11$)$ \\
\hline Intended vaginal delivery & 3888 & $68(1.7)$ & Reference & Reference & $8(0.2)$ & Reference \\
\hline \multicolumn{7}{|l|}{39 weeks: } \\
\hline Elective caesarean section & 1074 & $23(2.1)$ & $1.9(1.2$ to 3.0$)$ & $1.9(1.2$ to 3.0$)$ & $2(0.2)$ & 2.4 (0.5 to 12$)$ \\
\hline Intended vaginal delivery & 7755 & $89(1.1)$ & Reference & Reference & $6(0.1)$ & Reference \\
\hline \multicolumn{7}{|l|}{40 weeks: } \\
\hline Elective caesarean section & 132 & $2(1.5)$ & $0.9(0.2$ to 3.8$)$ & $0.9(0.2$ to 3.7$)$ & $0(0)$ & - \\
\hline Intended vaginal delivery & 11177 & $180(1.6)$ & Reference & Reference & $16(0.1)$ & \\
\hline \multicolumn{7}{|l|}{41 weeks: } \\
\hline Elective caesarean section & 47 & $1(2.1)$ & $1.4(0.2$ to 11$)$ & $1.5(0.2$ to 11$)$ & $0(0)$ & - \\
\hline Intended vaginal delivery & 7147 & $106(1.5)$ & Reference & Reference & $10(0.1)$ & \\
\hline \multicolumn{7}{|l|}{ Low risk pregnancies $\S(n=32580)$} \\
\hline \multicolumn{7}{|l|}{37 weeks: } \\
\hline Elective caesarean section & 191 & $20(10)$ & $4.2(2.4$ to 7.4$)$ & $3.8(2.1$ to 6.9$)$ & $3(1.6)$ & 3.2 (0.8 to 13$)$ \\
\hline Intended vaginal delivery & 1441 & $39(3.7)$ & Reference & Reference & $7(0.5)$ & Reference \\
\hline \multicolumn{7}{|l|}{38 weeks: } \\
\hline Elective caesarean section & 1083 & $55(5.1)$ & $3.3(2.3$ to 4.8$)$ & $3.3(2.2$ to 4.9$)$ & $9(0.8)$ & $4.2(1.6$ to 11$)$ \\
\hline Intended vaginal delivery & 3510 & $56(1.6)$ & Reference & Reference & $7(0.2)$ & Reference \\
\hline \multicolumn{7}{|l|}{39 weeks: } \\
\hline Elective caesarean section & 1051 & $22(2.1)$ & 1.8 (1.1 to 2.9 ) & 1.8 (1.1 to 2.9$)$ & $2(0.2)$ & $2.7(0.5$ to 14$)$ \\
\hline Intended vaginal delivery & 7339 & $86(1.2)$ & Reference & Reference & $5(0.1)$ & Reference \\
\hline \multicolumn{7}{|l|}{40 weeks: } \\
\hline Elective caesarean section & 127 & $2(1.6)$ & $1.0(0.2$ to 4.0$)$ & $1.0(0.2$ to 3.9$)$ & $0(0)$ & - \\
\hline Intended vaginal delivery & 10819 & 173 (1.6) & Reference & Reference & $14(0.1)$ & \\
\hline \multicolumn{7}{|l|}{41 weeks: } \\
\hline Elective caesarean section & 45 & $1(2.2)$ & $1.5(0.2$ to 11$)$ & $1.7(0.2$ to 12$)$ & $0(0)$ & 一 \\
\hline Intended vaginal delivery & 6974 & $102(1.5)$ & Reference & Reference & $10(0.1)$ & \\
\hline
\end{tabular}

*Adjusted odds ratio not calculated for serious respiratory morbidity owing to small number of observations.

†37 weeks $(37+0$ to $37+6), 38$ weeks $(38+0$ to $38+6)$, 39 weeks ( $39+0$ to $39+6), 40$ weeks $(40+0$ to $40+6)$, and 41 weeks $(41+0$ to $41+6)$.

†Adjusted for smoking, alcohol intake, parity, body mass index, marital status, maternal age, and years of schooling.

$\S$ Exclusion of pregnancies with diabetes mellitus, hypertension or pre-eclampsia, or intrauterine growth retardation. 
Table3 $\mid$ Odds ratios (95\% confidence intervals) of neonatal respiratory morbidity after elective caesarean section and intended vaginal delivery for 34458 pregnancies at Aarhus University Hospital, Denmark, 1998-2006

\begin{tabular}{|c|c|c|c|c|c|c|}
\hline \multirow[b]{2}{*}{ Gestational age $†$} & \multirow[b]{2}{*}{ No of deliveries } & \multicolumn{3}{|c|}{ Respiratory morbidity } & \multicolumn{2}{|c|}{ Serious respiratory morbidity* } \\
\hline & & No (\%) of infants & Odds ratio $(95 \% \mathrm{Cl})$ & Odds ratio $\ddagger(95 \% \mathrm{Cl})$ & No (\%) of infants & Odds ratio $(95 \% \mathrm{Cl})$ \\
\hline \multicolumn{7}{|l|}{37 weeks: } \\
\hline Elective caesarean section & 259 & $25(9.6)$ & 4.3 (2.6 to 7.2$)$ & $4.1(2.4$ to 7.0$)$ & $4(1.5)$ & $9.2(2.1$ to 42$)$ \\
\hline Intended vaginal delivery & 1772 & $43(2.4)$ & Reference & Reference & $3(0.3)$ & Reference \\
\hline \multicolumn{7}{|l|}{38 weeks: } \\
\hline Elective caesarean section & 1161 & $54(4.7)$ & $3.2(2.2$ to 4.6$)$ & 3.3 (2.2 to 4.8$)$ & $8(0.7)$ & $5.3(1.7$ to 16$)$ \\
\hline Intended vaginal delivery & 3831 & $58(1.5)$ & Reference & Reference & $5(0.1)$ & Reference \\
\hline \multicolumn{7}{|l|}{39 weeks: } \\
\hline Elective caesarean section & 1068 & $21(2.0)$ & 2.1 (1.3 to 3.4 ) & 2.1 (1.3 to 3.4$)$ & $0(0.0)$ & - \\
\hline Intended vaginal delivery & 7668 & $74(1.0)$ & Reference & Reference & $5(0.1)$ & \\
\hline \multicolumn{7}{|l|}{40 weeks: } \\
\hline Elective caesarean section & 131 & $2(1.5)$ & $1.2(0.3$ to 4.9$)$ & $1.2(0.3$ to 4.8$)$ & $0(0.0)$ & - \\
\hline Intended vaginal delivery & 11007 & $140(1.3)$ & Reference & Reference & $7(0.1)$ & \\
\hline \multicolumn{7}{|l|}{41 weeks: } \\
\hline Elective caesarean section & 46 & $1(2.2)$ & 1.9 (0.3 to 14$)$ & $2.0(0.3$ to 15$)$ & $0(0.0)$ & - \\
\hline Intended vaginal delivery & 6991 & $82(1.2)$ & Reference & Reference & $4(0.1)$ & \\
\hline
\end{tabular}

Infants with meconium aspiration syndrome, sepsis, or pneumonia excluded.

*Adjusted odds ratio not calculated for serious respiratory morbidity owing to small number of observations.

$\dagger 37$ weeks $(37+0$ to $37+6), 38$ weeks $(38+0$ to $38+6)$, 39 weeks ( $39+0$ to $39+6), 40$ weeks $(40+0$ to $40+6)$, and 41 weeks $(41+0$ to $41+6)$.

$\ddagger$ Adjusted for smoking, alcohol intake, parity, body mass index, marital status, maternal age, and years of schooling.

(table 2). Bivariate analyses were repeated for low risk pregnancies, which resulted in slightly higher risk estimates (table 2).

Exclusion of newborns with meconium aspiration syndrome, sepsis, or pneumonia resulted in an increased risk in infants delivered by elective caesarean section regardless of gestational age, and the results tended towards slightly higher risk estimates (table 3).

The risk of respiratory morbidity after elective caesarean section in each gestational week was compared with the risk after intended vaginal delivery at 40 weeks' gestation (table 4). A significantly increased risk was found for infants delivered by elective caesarean section at 37 and 38 weeks' gestation. Delivery by elective caesarean section at 39 weeks' gestation still showed an increased risk of respiratory morbidity when compared with intended vaginal delivery at 40 weeks' gestation, despite no longer being statistically significant.

\section{Serious respiratory morbidity}

The risk of serious respiratory morbidity was increased in babies delivered by elective caesarean section in each of the gestational weeks 37 to 39 compared with babies delivered during the same weeks after intended vaginal delivery (table 2). The relative risk increased with decreasing gestational age but the risk estimates were all higher than those for respiratory morbidity in general, with a fivefold increase for infants delivered at 37 weeks' gestation, a fourfold increase for infants delivered at 38 weeks, and a more than twofold increase for infants delivered at 39 weeks, although the increased risk at 39 weeks was not statistically significant.

Analyses after restriction to low risk pregnancies showed slightly smaller relative risk estimates at
37 weeks' gestation but essentially unchanged estimates at 38 and 39 weeks (table 2).

Exclusion of babies with meconium aspiration syndrome, sepsis, or pneumonia resulted in higher relative risk estimates for babies delivered at 37 and 38 weeks' gestation (table 3 ).

When the risk of serious respiratory morbidity after elective caesarean section at different gestational ages was compared with the risk after intended vaginal delivery at 40 weeks' gestation, a high increased risk of serious respiratory morbidity was found for newborns delivered by elective caesarean section at 37 weeks' gestation (13.6, 5.1 to 36 ; table 4). The risk remained increased at 38 and 39 weeks' gestation. The increased risk at 39 weeks was not, however, statistically significant.

\section{DISCUSSION}

The risk of neonatal respiratory morbidity after elective caesarean section in singletons born at Aarhus University Hospital, Denmark, between 1 January 1998 and 31 December 2006 was twice to four times that after intended vaginal delivery within each gestational week from 37 to 39 weeks. When the risk of respiratory morbidity after elective caesarean section in each gestational week was compared with the risk after intended vaginal delivery at 40 weeks' gestation, the relative risk decreased from seven times higher at 37 weeks to three times higher at 38 weeks, whereas the relative risk at 39 weeks was no longer statistically significant.

Even among term deliveries we found a major modification of the association between elective caesarean section and respiratory morbidity by gestational age, with the earlier elective caesarean sections associated more with respiratory morbidity than the 
later caesarean sections. This was found even when comparing with babies intended for vaginal delivery during the same gestational week, which for the earlier deliveries at term is not the most likely alternative because most spontaneous vaginal deliveries take place at 40 weeks or later.

\section{Comparison with other studies}

A previous large cohort study aimed to establish whether timing of delivery by elective caesarean section between 37 and 42 weeks' gestation influenced respiratory morbidity in neonates. ${ }^{17}$ Elective caesarean section at different gestational ages was compared with vaginal deliveries at 40 weeks' gestation without taking into account the intended vaginal deliveries that resulted in emergency caesarean sections. Exclusion of emergency caesarean sections from the comparison group could have resulted in an overestimation of the effect of elective caesarean section because of the exclusion of sick newborns. This is in keeping with higher risks estimated by the authors, who found a frequency of respiratory morbidity of 5.2 per 1000 infants in their comparison group, whereas the frequency in our comparison group was as high as 16 per 1000 infants. We analysed our data in an adapted intention to treat manner-that is, we included emergency caesarean sections in the comparison group - which gave odds ratios lower than the ones in the large cohort study. ${ }^{17}$

All other studies on this subject failed to take gestational age into consideration or handled it as a potential confounder. They also reported one risk estimate for respiratory morbidity in term infants, regardless of the potentially large modification of the effect from gestational ages 37 to 40 weeks. ${ }^{10}$

\section{Strengths and weaknesses of the study}

Data in our study were collected prospectively. Information on type of delivery was validated by research midwives before data entry, and information on respiratory morbidity was provided by neonatologists. Variation may exist in the use of the international classification of diseases, 10th revision, codes for respiratory morbidity (transient tachypnoea of the newborn, respiratory distress syndrome, and persistent pulmonary hypertension of the newborn). This could influence the results if separate analyses for subgroups of respiratory morbidity were carried out, especially because some of the subgroups would be of limited size. By analysing respiratory morbidity as one unit we sought to avoid this possible imprecision. We also repeated the analyses by looking at intervention categories (ventilatory support, need of oxygen, and nasal continuous positive airway pressure) rather than diagnostic categories. These analyses corroborated our initial findings of an increased risk of significant respiratory morbidity that increased with decreasing gestational age around term. To test potential effects of confounding by indication we repeated all analyses for the group of low risk pregnancies but found no influence on the estimated risk of respiratory morbidity.

Information about elective caesarean sections as a result of patient choice (maternal request) was available for the later part of our study period (2002-6). During this period 788 women had a caesarean section by patient choice. Repeated analyses of these showed risk estimates similar to those calculated for our low risk population. Because of the small numbers involved, the confidence intervals derived from 37, 40, and 41 weeks' gestation were wide although the estimates were not statistically different from those presented (data not shown).

Several other relatively rare conditions might influence the risk of neonatal respiratory morbidity. We therefore repeated our analyses after exclusion of infants born to women given steroids during pregnancy $(\mathrm{n}=383)$ or selective serotonin reuptake inhibitors

Table 4 | Odds ratios (95\% confidence intervals) of respiratory morbidity after elective caesarean section compared with intended vaginal delivery at 40 weeks gestation in 34458 pregnancies at Aarhus University Hospital, Denmark, 1998-2006

\begin{tabular}{|c|c|c|c|c|c|c|}
\hline \multirow[b]{2}{*}{ Gestational age $\nmid$ and type of delivery } & \multirow[b]{2}{*}{ No of deliveries } & \multicolumn{3}{|c|}{ Respiratory morbidity } & \multicolumn{2}{|c|}{ Serious respiratory morbidity* } \\
\hline & & $\begin{array}{l}\text { No (\%) of } \\
\text { infants }\end{array}$ & Odds ratio $(95 \% \mathrm{Cl})$ & Odds ratio $\ddagger(95 \% \mathrm{Cl})$ & $\begin{array}{l}\text { No (\%) of } \\
\text { infants }\end{array}$ & Odds ratio $(95 \% \mathrm{Cl})$ \\
\hline \multicolumn{7}{|l|}{37 weeks: } \\
\hline Elective caesarean section & 261 & $26(10.0)$ & $6.8(4.4$ to 10$)$ & 7.0 (4.5 to 11$)$ & $5(1.9)$ & $13.6(5.1$ to 36$)$ \\
\hline \multicolumn{7}{|l|}{38 weeks: } \\
\hline Elective caesarean section & 1173 & $60(5.1)$ & $3.3(2.4$ to 4.4$)$ & 3.5 (2.6 to 4.8$)$ & $10(0.9)$ & $6.0(2.8$ to 13$)$ \\
\hline \multicolumn{7}{|l|}{39 weeks: } \\
\hline Elective caesarean section & 1074 & $23(2.1)$ & $1.3(0.9$ to 2.1$)$ & 1.4 (0.9 to 2.2$)$ & $2(0.2)$ & $1.3(0.0$ to 5.1$)$ \\
\hline \multicolumn{7}{|l|}{40 weeks: } \\
\hline Elective caesarean section & 132 & $2(1.5)$ & 0.9 (0.0 to 3.5$)$ & 0.9 (0.2 to 3.7$)$ & $0(0.0)$ & - \\
\hline $\begin{array}{l}\text { Intended vaginal delivery } \\
\text { (Reference) }\end{array}$ & 11177 & $180(1.6)$ & Reference & Reference & $16(0.1)$ & Reference \\
\hline \multicolumn{7}{|l|}{41 weeks: } \\
\hline Elective caesarean section & 47 & $1(2.1)$ & $1.3(0.0$ to 7.7$)$ & 1.3 (0.2 to 9.8$)$ & $0(0.0)$ & - \\
\hline
\end{tabular}

*Adjusted odds ratio not calculated for serious respiratory morbidity owing to small number of observations.

$\dagger 37$ weeks $(37+0$ to $37+6), 38$ weeks $(38+0$ to $38+6)$, 39 weeks ( $39+0$ to $39+6), 40$ weeks $(40+0$ to $40+6)$, and 41 weeks $(41+0$ to $41+6)$.

†Adjusted for smoking, alcohol intake, parity, body mass index, marital status, maternal age, and years of schooling. 


\section{WHAT IS ALREADY KNOWN ON THIS TOPIC}

Elective caesarean section has been associated with increased risk of neonatal respiratory morbidity

This has been attributed to "iatrogenic prematurity" or lack of physiological changes related to labour

\section{WHAT THIS STUDY ADDS}

Babies delivered by elective caesarean section at 37 to 39 weeks' gestation are at twofold to fourfold increased risk of respiratory morbidity compared with babies delivered by intended vaginal delivery

A reduction in neonatal respiratory morbidity may be obtained if elective caesarean section is postponed until 39 completed weeks of gestation

during pregnancy $(\mathrm{n}=244)$. Our risk estimates did not change. Exclusion of babies in breech presentation $(n=1325)$ also failed to change our estimates (data not shown).

In a proper intention to treat analysis women who were originally scheduled for elective caesarean section but had emergency caesarean sections (categorised as intended vaginal delivery in our analyses) should have been categorised as elective caesarean sections. We repeated our analyses after recategorising these women and found no significant change in the risk estimates (data not shown).

\section{Meaning of the study}

Even when elective caesarean section was carried out at 39 completed weeks of gestation an increased risk of respiratory morbidity remained evident in our study, as is the case in a few other studies. ${ }^{17}$ Lack of hormones associated with labour could explain this association. During spontaneous labour there is a decrease in secretion of fetal lung liquid and an increase in its absorption and the release of surfactant is stimulated. This may be mediated by a raised level of catecholamines in the fetus in response to rupture of membranes and labour. ${ }^{14}$ When caesarean sections are carried out before labour this catecholamine surge is absent. Studies have shown significantly lower levels of catecholamines and changes in lung function in term babies delivered by elective caesarean section compared with babies delivered vaginally. ${ }^{18}$

Some have suggested that giving corticosteroids during the antenatal period to women who deliver by elective caesarean section might reduce neonatal respiratory morbidity. This was tested in a randomised controlled trial, which showed that betamethasone given during the antenatal period reduced neonatal respiratory morbidly as did delaying delivery until 39 weeks' gestation. ${ }^{20}$ The long term safety of antenatal steroid administration is, however, still being debated. $^{21}$

\section{Implications}

Our results support the notion that the risk of overall and serious respiratory morbidity is increased in newborns delivered by elective caesarean section. Our results also suggest that a significant reduction in neonatal respiratory morbidity may occur if elective caesarean section is postponed to 39 weeks' gestation. Carrying out elective caesarean sections at greater gestational ages may, however, result in higher rates of intrapartum caesarean sections because some women would go into spontaneous labour (in our population $25 \%$ of spontaneous intended vaginal deliveries started before 39 weeks' gestation). Compared with elective caesarean sections, intrapartum caesarean sections may carry an increased risk of complications such as uterine rupture in women with previous caesarean section, infections, or even maternal mortality. ${ }^{22}$ In contrast the influence of labour or rupture of membranes before caesarean section may be beneficial to newborns. ${ }^{24}$

Only observational studies have attempted to evaluate the risks and benefits of elective caesarean section for pregnant women and newborns. ${ }^{10}$ More evidence based information on the effect of timing and caesarean section in labour could be obtained from randomised controlled trials, which would have to have large populations.

\section{Conclusion}

This study suggests that elective caesarean section compared with intended vaginal delivery leads to a twofold to fourfold increased risk of overall neonatal respiratory morbidity and even higher relative risks of serious respiratory morbidity in term newborns. Our results also suggest that a significant reduction in neonatal respiratory morbidity may be obtained if elective caesarean section is postponed to 39 weeks' gestation. This information should be taken into consideration by women contemplating an elective caesarean section and by the obstetricians counselling them.

Contributors: AKH conceived and designed the study, analysed and interpreted the data, and drafted the article. She is guarantor. KW and NU interpreted the data and revised the article. TBH conceived and designed the study, interpreted the data, and revised the article. All authors approved the final version.

Funding: This study was supported by the Clinical Institute, Aarhus University, the Research Initiative, Aarhus University Hospital, and Aase and Einer Danielsens Fund.

Competing interests: None declared

Ethical approval: Not required.

Provenance and peer review: Not commissioned; externally peer reviewed.

1 VillarJ, Valladares E, Wojdyla D, Zavaleta N, Carroli G, Velazco A, et al. Caesarean delivery rates and pregnancy outcomes: the 2005 WHO global survey on maternal and perinatal health in Latin America. Lancet 2006;367:1819-29.

2 Murray SF. Relation between private health insurance and high rates of caesarean section in Chile: qualitative and quantitative study. $B M$ J 2000;321:1501-5.

3 Al-Mufti R, McCarthy A, Fisk NM. Survey of obstetricians' personal preference and discretionary practice. Eur J Obstet Gynecol Reprod Biol 1997;73:1-4.

4 Bergholt T, Ostberg B, Legarth J, Weber T. Danish obstetricians' personal preference and general attitude to elective cesarean section on maternal request: a nation-wide postal survey. Acta Obstet Gynecol Scand 2004;83:262-6.

5 Scott JR. Cesarean delivery on request: where do we go from here? Obstet Gynecol 2006;107:1222-3. 
6 Hannah ME. Planned elective cesarean section: a reasonable choice for some women? CMAJ 2004;170:813-4.

7 Jackson NV, Irvine LM. The influence of maternal request on the elective caesarean section rate. J Obstet Gynaecol 1998;18:115-9.

8 Kolas T, Hofoss D, Daltveit AK, Nilsen ST, Henriksen T, Hager R, et al. Indications for cesarean deliveries in Norway. Am J Obstet Gynecol 2003;188:864-70.

9 ACOG Committee Opinion. Surgery and patient choice: the ethics of decision making. Obstet Gynecol 2003;102(5 Pt 1):1101-6.

10 Hansen AK, Wisborg K, Uldbjerg N, Henriksen TB. Elective caesarean section and respiratory morbidity in the term and near-term neonate. Acta Obstet Gynecol Scand 2007;86:389-94.

11 Walters DV, Olver RE. The role of catecholamines in lung liquid absorption at birth. Pediatr Res 1978;12:239-42.

12 Lawson EE, Brown ER, Torday IS, Madansky DL, Taeusch HW Ir. The effect of epinephrine on tracheal fluid flow and surfactant efflux in fetal sheep. Am Rev Respir Dis 1978;118:1023-6.

13 Wennergren M, Krantz M, Hjalmarson O, Karlsson K. Interval from rupture of the membranes to delivery and neonatal respiratory adaptation. Br J Obstet Gynaecol 1986;93:799-803.

14 Brown MJ, Olver RE, Ramsden CA, Strang LB, Walters DV. Effects of adrenaline and of spontaneous labour on the secretion and absorption of lung liquid in the fetal lamb. J Physiol 1983;344:137-52.

15 Irestedt L, Lagercrantz H, Hjemdahl P, Hagnevik K, Belfrage P. Fetal and maternal plasma catecholamine levels at elective cesarean section under general or epidural anesthesia versus vaginal delivery. Am J Obstet Gynecol 1982;142:1004-10.
16 Faxelius G, Hagnevik K, Lagercrantz H, Lundell B, Irestedt L. Catecholamine surge and lung function after delivery. Arch Dis Child 1983;58:262-6.

17 Morrison JJ, Rennie JM, Milton PJ. Neonatal respiratory morbidity and mode of delivery at term: influence of timing of elective caesarean section. Br J Obstet Gynaecol 1995;102:101-6.

18 Madar J, Richmond S, Hey E. Surfactant-deficient respiratory distress after elective delivery at "term." Acta Paediatr 1999;88:1244-8.

19 Wisborg K, Kesmodel U, Bech BH, Hedegaard M, Henriksen TB. Maternal consumption of coffee during pregnancy and stillbirth and infant death in first year of life: prospective study. BMJ 2003;326:420

20 Stutchfield P, Whitaker R, Russell I. Antenatal betamethasone and incidence of neonatal respiratory distress after elective caesarean section: pragmatic randomised trial. BMJ 2005;331:662.

21 Steer PJ. Giving steroids before elective caesarean section. BM] 2005;331:645-6.

22 Lilford RJ, van Coeverden de Groot HA, Moore PJ, Bingham P. The relative risks of caesarean section (intrapartum and elective) and vaginal delivery: a detailed analysis to exclude the effects of medical disorders and other acute pre-existing physiological disturbances. $\mathrm{Br}$ J Obstet Gynaecol 1990;97:883-92.

23 Bowers SK, MacDonald HM, Shapiro ED. Prevention of iatrogenic neonatal respiratory distress syndrome: elective repeat cesarean section and spontaneous labor. Am J Obstet Gynecol 1982;143:186-9.

24 Cohen M, Carson BS. Respiratory morbidity benefit of awaiting onset of labor after elective cesarean section. Obstet Gynecol 1985;65:818-24.

Accepted: 4 November 2007 